\title{
Extension of the Piccadilly Line from Hounslow West to Heathrow Central
}

\author{
D. G. JOBLING \& A. C. LYONS
}

\section{Mr T. A. Clark, W. \& C. French (Construction) Ltd}

My remarks and comments are confined to Contract 393, the cut-and-cover section of the project between Hounslow West and Hatton Cross, this being the contract carried out by my company.

151. Some concern was expressed at the start of the contract that this section of the project, when finally constructed, might disturb the groundwater conditions in the area, projecting as it does above the existing water-table level throughout its length, thereby forming a barrier some $3.5 \mathrm{~km}$ long across the natural N-S flow of the groundwater towards the Thames. As a result instructions were to construct a number of siphons under the tunnel to provide relief should this situation arise. Would the Authors please comment on whether build-up of groundwater has in fact occurred on the north side of the tunnel despite the introduction of these relief siphons?

152. In $\$ 32-37$, the Authors describe the manner in which the statutory services and traffic diversions were carried out. I would especially commend the manner in which these items were dealt with concerning payment as described in $\S 37$ : they were removed completely from the competitive element of the tender, thereby permitting much freer discussion on these subjects during the construction period.

153. Management of these and all other constructional works was controlled by means of computer printouts from the contract activity network with activities arranged in order of 'float times'. Special printouts for long running activities, such as secant piling, precast concrete beam supply and placing and anti-vibration track tray supply and placing were also produced. The setting-out of the contract was also computerized by means of a Hewlett Packard 9100 B table-top computer with a printout addition, thus relieving the setting-out engineers of much tedious calculation work.

154. With regard to the excavation work, the contract differentiated between excavating in ballast and excavating in clay. Anyone with experience of working in the London Airport area will know that the ballast is in fact of good quality, and consequently, separation of the two materials to be dug was a commercial proposition. Our tender was based on carrying this out by the conventional methods described in $\S 43$ and the removal of excavated material by means of the conveyor was largely experimental, the commercial viability of the conveyor system being satisfied by the concreting operation alone.

155. Concrete for the whole contract was supplied from a central batcher by means of six $4.6 \mathrm{~m}^{3}$ Ransome Rapier truck mixers on Ford chassis and, in view of the great variety of depositing points for the concrete, they were fitted with single balloon tyres on both rear axles in place of the conventional double tyres in order to eliminate as far 
as possible the deposition of soil on public roads. The co-ordination of concrete deliveries was organized by means of two-way radio, using a VHF low band frequency in order not to interfere with airport communications.

\section{Mr H. Stone, Lilley-Waddington Ltd}

The secant piling has been covered very well in the Paper, but there are certain aspects of it to which I should like to draw attention. The boring of the secant piles, which are fully cased to the full depth, is a very safe method of construction, which prevents any loss of ground. The piling was in fact that best suited to the construction required in the short advanced stretches of work which had to be constructed to allow the permanent diversion of the services. My company installed very short stretches of piling, indeed as low as five piles in each wall. The mobility of the equipment made it possible to pile for such short stretches and move out again and let the main contractor roof that section and deal with the services to be diverted. In the first ten months of the contract any one rig was employed only on one wall in any one location for up to two weeks. This meant that the rigs were continually moving up and down to install the early service diversions.

157. In general the strata were not as we were led to believe. There was more water in these locations, especially at the west end of the contract. In order to combat this we could either reduce the pile centres-which would cost more and increase the time required-or transfer the ballast and keep the pile centres spread as far apart as possible, which could lead to remedial works. The cost of remedial works may be far less than that of tightening the piles and reducing the centres, but another aspect one has to consider in regard to remedial works is to what extent this will interfere with the main contractor's programme. On the whole I think the right decision was made, because the amount of remedial work required was relatively small and there was little interference with the main contractor's programme.

158. I would ask the Authors about the economics of secant piling in comparison with the standard box section which was constructed in sheet piling. By the factory there was a very deep section where secant piles had to be very heavily reinforced. How does the subsequent construction compare with the standard construction in the area where sheet piling was used?

\section{Mr K. Møller, Soil Mechanics Ltd}

The Authors refer to two separate instances of ground treatment used to overcome unstable soil conditions ( $\$ 36$ and 114-116). These projects, which were carried out by my company, both involved chemical grouting of waterbearing gravels to safeguard tunnelling operations.

160. Treatment for the sewer heading near Henley's Corner was put in hand at very short notice after the unexpected presence of gravel in the face had resulted in a collapse. The chemicals were injected through lances driven from the surface, penetrating well into the underlying clay to ensure a seal at the clay/gravel interface which occurred within the heading. The water-table stood some $4.50 \mathrm{~m}$ above the interface and very little seeped through the treated soil.

161. The second instance occurred at the breakout of the running tunnels in enlarged diameter into the Heathrow Central station cofferdam. Prior knowledge of the presence of gravel in the crown of the twin enlargements made it possible to take preventive measures before tunnelling had advanced to this position. Lance driving was not feasible due to the length of drive and the configuration of raking pipes which was necessary to avoid occupation of the airport inner ring road. Therefore injections were made through preinstalled tubes à manchette. This system made it practicable to use the cheaper cement-bentonite grouts to fill the major pores before chemicals were injected for the final sealing. Careful control of heave was required during grout injections to preserve intact the overlying airport SPV and other services. 
Mr J. R. J. King, John Mowlem \& Co. Ltd

The contract was won by one piece of sound practical experience and two bold innovations. The sound experience was in the method of constructing the cut-and-cover section. Sheet piling which formed the cut-off was driven in the battered upper excavation, thus saving the need for support of the cut-off piling. Soldier piles were then dropped into bored holes around the perimeter of the structure. The tubular struts to the soldier piles and the in situ concrete cross poling between them were placed as the excavation proceeded.

163. The method made it possible to develop six or seven successive operations in echelon, allowing rapid progress, working from the western end of the cut-and-cover section, and enabled an early start to tunnelling. Height restrictions made it impossible to use the normal winding gear for disposal of spoil and conveyors were introduced for handling tunnel spoil.

164. The bold innovations were in the first major use of roadheader type tunnel excavators in conjunction with hand shields, and in the manufacture of running tunnel segments by hydraulic pressing. The options at the time of tender for the running tunnel drives were for hand shields similar to those used on the Victoria Line backed up by conveyors and segment erectors, or full faced drum digger shields. It was felt from experience on the Victoria Line that full faced drum digger shields were expensive in fitters' time and in down-time, but on the other hand, hand shields, which were simple to operate and maintain, would require three $8 \mathrm{~h}$ shifts working with six gangs of five highly skilled miners. We did not feel confident that we could attract sufficient skilled miners to London Airport to man the hand shields. The bid was therefore priced on the basis of part-faced tunnelling machines, but it was not decided at the time of tender whether this should be a Westphalia boom cutter or an Anderson Mavor rotary machine. The Westphalia boom cutter has its own in-built loading mechanism (the cutting mechanism has teeth rotating upwards which deposit the excavated spoil onto an integral conveyor system for loading into skips). On the other hand with the Anderson Mavor roadheader machine the spoil is dropped into the invert for reloading onto conveyors by separate equipment.

165. It was difficult to make the decision principally because both methods were substantially untried. The Westphalia had been used once for a London Post Office cable tunnel. The Anderson Mator machine was much more robust, but access to the tunnel face was limited and it required an untried method of loading spoil.

166. In the event, we decided to try both machines, using one in each tunnel. On completion of the drives it was not entirely clear which machine was the better. They differ in the ranges of diameters they can cover, the clay strengths which they will cut, their purchase costs, the reliability in down-time, operator expertise required, spare cost and availability and, last but not least, safety in use. Both these machines are being reused on another contract which is an indication that both were successful. In passing I should like to give credit to Anderson Mavor for the excellent service their field teams gave to the contract.

167. The second innovation was the use of hydraulic pressing of the tunnel segments. A $400 \mathrm{t}$ three mould rotary press was used which had previously only been used for pressing such items as bricks, kerbs and paving slabs, but never for such a sophisticated shape as a tunnel segment.

168. These segments had domed faces with an $11.25 \mathrm{~m}$ radius in one direction and a $3.0 \mathrm{~m}$ radius in the other. Tolerances were $0.305 \mathrm{~mm}$ on the $11.25 \mathrm{~m}$ and $0.051 \mathrm{~mm}$ on the $3.0 \mathrm{~m}$ radius. In hindsight, more time than was available was needed from the commencement of the contract to the commencement of tunnel driving to allow for experimentation and trials as well as for manufacture of a stockpile of segments. Eventually production had to be double shifted to maintain a supply to the drives. A much greater length of tunnel would be needed to make the experiment viable.

169. The amount of concrete poured into the mould had to be extremely accurate 


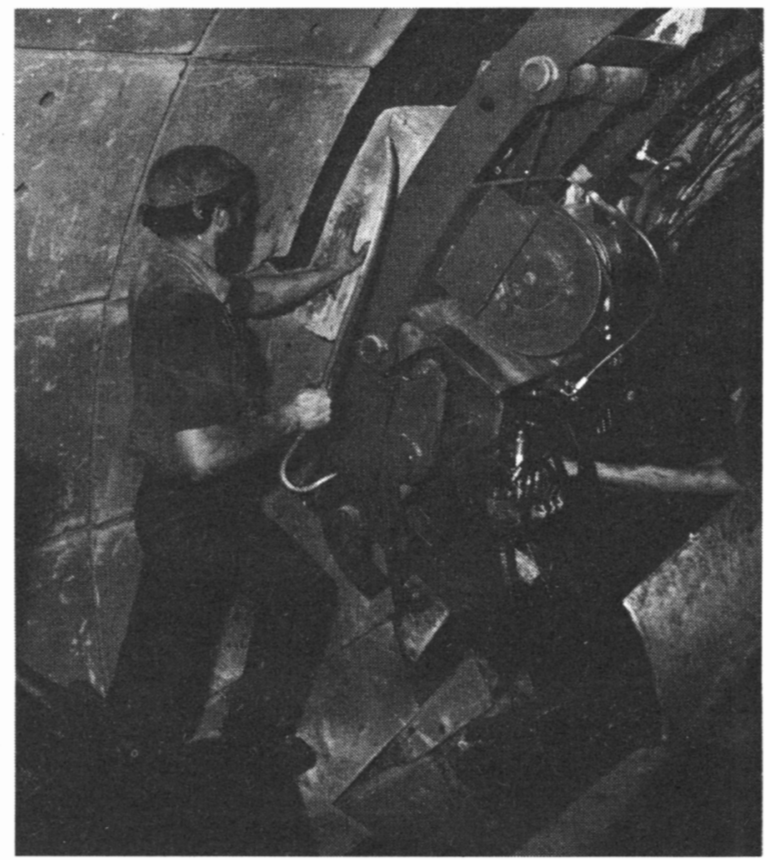

Fig. 13. Westbound tunnel: building $3810 \mathrm{~mm}$ lining with Lawrence shield

so that the manufacturing tolerances would not be exceeded. The table rotates so that in one position the mould is being filled, simultaneously in another position the segment is being pressed and in the third position the mould is ejected and the segment removed. There is a moment of truth when the segment is ejected from the mould and simultaneously the vacuum pad lifts it up. The segment is transported by the vacuum pad, turned onto its edge and set down onto a roller path for removal by forklift truck. When it was running well-and by no means was it always running well-it took less time to manufacture a segment than it has taken me to describe.

170. Part of the tunnel was driven with segments that were surplus from the Victoria Line, but the bulk of the tunnel was made with the new Halcrow design. The Mott Hay and Anderson lining gave better facilities for alignment and control of the roll, but the invert segments which were integral with a flat surface for the permanent way track were very bulky to handle. In these days when there is a lot of machinery inside tunnels, one prefers a smaller segment for safety and speed in handling.

171. The Halcrow segments to my mind were designed to far too tight a tolerance. Even the manufacturer of the steel moulds had difficulty in machining them to such a close tolerance. They proved difficult to wedge, but they were the right sort of size to handle without damage either to segment or to the operatives.

172. I feel it would be helpful if those who are devising new techniques for building tunnels and those who are manufacturing segments had more opportunity to get together with those who are designing tunnel linings in order to pool their ideas. There is a case for standardization, at least pro tem, whilst new ideas are consolidated.

173. I come now to a particular problem with any wedge block lining. Fig. 13 shows the ring being erected with the wedge segment (here at knee level each side) partially inserted. The cross joint of the wedge segments and those of the mating 
segments have helical surfaces to accommodate the change in radial position when the wedge segments are pushed home by special rams in the shield. The $80 \mathrm{~mm}$ horizontal movement available in the wedging operation gives rise to a maximum of $5 \mathrm{~mm}$ travel round the circumference for expanding the ring. This is quite insufficient for the range and variety of movement of clays cut by the shield. This movement after cutting varies from zero to possibly $30 \mathrm{~mm}$ in my experience. Possible solutions are to provide wedge segments of different thicknesses together with additional packing plates for fine adjustment, or to alter the diameter of the cut by the use of clip-on beads attached to the shield-both of which are time-consuming and inappropriate to machine tunnellingor to revert to expanding the ring by hydraulic jacks. It would be useful to hear other views on the relative merits of horizontal wedging and vertical jacking.

174. Finally, the contract was unfortunately affected by a number of changes due to external factors: these were frustrating at the time. Much credit is due to the site staff for the way they used initiative, innovation and plain common sense to get the job done and to Halcrow's staff for the way in which they co-operated in overcoming the problems.

\section{Mr P. Sims, L. G. Mouchel \& Partners}

I visited a portion of the work whilst it was in progress and was particularly impressed by the secant piling method of forming the walls and the high rate of progress being achieved by the subsequent operations necessary to complete the section. In particular the alignment of the piles was good and the extent of water leakage low. The distorted condition of the driven steel sheet piling in the concrete box section was very instructive. The Authors have suggested that the box section would have been cheaper than the secant construction for the whole of the work but, having seen the state of the steel piling, I would expect the box section to have proved expensive for someone.

176. The Authors state that the British Airports Authority will construct a subway from the station to each of the passenger terminal buildings. I would like to comment on this final link of the project, particularly those aspects which relate to the Paper.

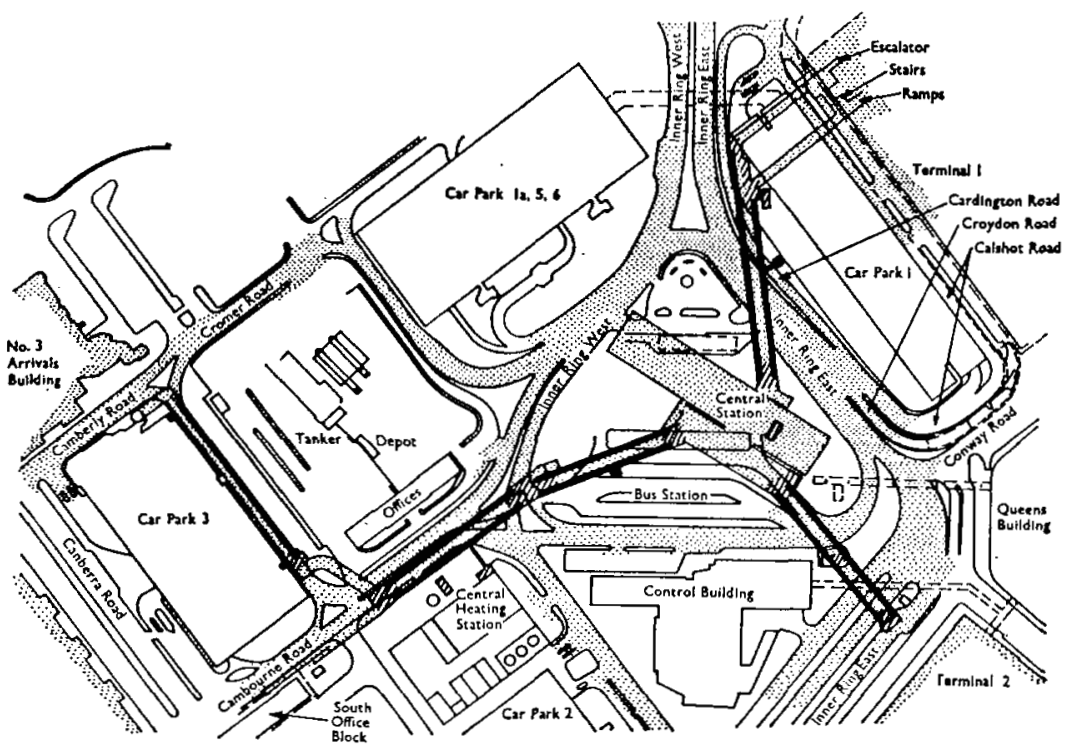

Fig. 14. Layout of Heathrow airport 
The passenger subways are slightly wider than the cut-and-cover section of the railway, having two $1.4 \mathrm{~m}$ wide Travolators and a central walkway within a total structural width of $8.5 \mathrm{~m}$. The subway roof is generally at a lower level to cater for present and future services. The passenger and traffic activities in the Central Terminal area at Heathrow are very sensitive to interference and the impact of major civil engineering works on the scene requires careful consideration and planning to minimize these effects. Fig. 14 shows the layout of the subways in relation to the station and the terminal buildings.

177. The civil engineering construction of the subways breaks down into three elements: (a) main subway runs; $(b)$ single width subways passing through the multistorey car park and into Terminal 1 ; (c) foyer area. The design problems of the main subway runs are essentially similar to those mentioned in the Paper but, due to the large number of service crossings and diversions, coupled with the high traffic flow, it is necessary to carry out the work in small areas to suit a phased programme of road diversions. In all some 250 services cross the route and vary from quite small pipes to a $3 \mathrm{~m}$ square cable tunnel.

178. The selected design for the main subways is similar to that used by the Authors and incorporates the use of secant piles where possible. These are chosen for their economy and flexibility in dealing with the smaller lengths of wall and the absence of bentonite. In a number of places it has been either uneconomic or impractical to divert major services, and here the secant walls are stopped short of the service. The ground below the service has been chemically injected and the section of wall completed in reinforced concrete after the main tunnel has been excavated.

179. The advantages of avoiding deep excavation on the line of roads in the centre of Heathrow are perhaps obvious and do not require emphasis. Substantial areas of the roof have been formed in in situ reinforced concrete where for constructional reasons it has not been possible to use precast prestressed units.

180. Single subways without Travolators connect the main tunnels to the NW corner of terminal building 1, passing below the multi-storey car park. A mixture of low headroom secant piles and bored piles has been used to form the walls of these subways which pass between and below the foundations of the car park. To reduce lateral pressures on the walls and associated settlement of the adjoining foundations, the gravel beneath the foundations has been chemically injected prior to excavation of the subway. Using these methods, traffic flow through the car park has been maintained. A similar procedure has been used for forming the underground connexions inside the terminal building.

181. The other major section of the work is the foyer joining the subways leading to terminals 2 and 3 and adjoining the station ticket hall. This structure is $75 \mathrm{~m} \times 18 \mathrm{~m}$ in plan.

\section{Mr T. H. L. Morgan, Sir William Halcrow \& Partners}

The $2 \mathrm{~m}$ thick roof slab of Heathrow Central station is designed to carry a building up to six storeys high and because of this rather unusual type of loading the design and construction method incorporated some interesting features. I should like to add to the description in the text of the Paper some details of the design considerations necessary to the development of a suitable method of construction with particular emphasis upon the special precautions taken.

183. The majority of early work on the $2 \mathrm{~m}$ slab presumed casting in one lift, but, in the event, the Contractor proposed to cast in two lengths. As works progressed it became desirable that the method of construction of the roof slab should suit, as far as possible, temporary works materials already available on site and the techniques and skills developed during construction of the ticket hall and mezzanine flat slabs, in order to achieve economy in construction. It was also important to save as much time as possible and maintain the greatest degree of access to lower levels so that other work could proceed without interruption. 
184. In co-operation with the Contractor, various combinations of first and second lift depths were considered using the following preconditions. From the point of view of the contractor these were $(a)$ a re-use of readily available falsework with a minimum amount of modification; $(b)$ a minimum amount of additional reinforcement in the $2 \mathrm{~m} \mathrm{slab}$; $(c)$ a minimum amount of through-propping to lower levels. From the point of view of the engineer they were: $(d)$ maintenance of overstress in lower level slabs within reasonable limits; $(e)$ confidence that stress levels in the completed $2 \mathrm{~m}$ slab left sufficient residual capacity to carry the final loads with no overstress; $(f)$ some knowledge of the effects of thermal and drying shrinkage stresses in the new circumstances, particularly during hydration of the second lift.

185. Since the available falsework had been designed to carry a maximum of $400 \mathrm{~mm}$ of concrete, the main object was to keep the first lift as thin as possible. Unfortunately, this made the conditions $(a)$ and $(b)$ mutually incompatible unless considerable extra support were provided to the first lift during the remaining operation.

186. At this point it should be explained that a persistent problem throughout construction of the flat slabs had been assessment of the effectiveness of supporting measures to slabs required to carry temporary works loads considerably in excess of their service loads. The main difficulty was to estimate the support condition provided by steel props of low stiffness when the load was being transmitted via highly redundant and relatively stiff slabs. Tests carried out by the Central London Polytechnic on a proprietary steel shore rated at $20 \mathrm{t}$ showed a deflexion of $10 \mathrm{~mm}$ at the rated load, but the stiff slabs carry their service loads at deflexions of $2 \mathrm{~mm}$ or less, and therefore shoring might only be $20 \%$ efficient at the point of maximum slab deflexion.

187. Propping the ticket hall and mezzanine slabs so that serious overstress did not occur during casting of the first lift of the $2 \mathrm{~m}$ slab was achieved by assuming $20 \%$ efficiency in props and an allowable overstress of about $25 \%$ in lower levels; any deficiency in this estimate was allowed for as additional overstress in the slabs which might rise to $40 \%$ or $50 \%$ without causing damage.

188. Completed slabs recover elastically from any short-term overstress of reasonable magnitude, but this would not have occurred in the first lift of the $2 \mathrm{~m}$ slab which, under the load of the second lift when set would be locked into its deflected shape. Similarly, steel stresses in the bottom of the first lift would not be able to adjust as construction proceeded. The contribution of support provided by shoring was known to be low, but if underestimated--even by a small amount-the bottom tensile reinforcement in the completed $2 \mathrm{~m}$ slab would finally be overstressed by an unknown degree. In view of the nature of the final loading, this risk could not be entertained. It was decided therefore that the first lift should be designed to carry the second lift unaided by any additional support. Provision of extra reinforcement was made so that final loads could be carried at working stresses.

189. A $600 \mathrm{~mm}$ first lift was initially proposed since the falsework could carry this load with only minor modifications. Upon consideration it was found that the slab, having a depth only $30 \%$ of the final section, suffered from a number of disadvantages:

(a) temporary applied bending moments were greater than $50 \%$ of the moment of resistance of the $600 \mathrm{~mm}$ section and considerable quantities of additional reinforcement were required; bottom tensile steel was already in four layers of large diameter bars and together with the additional steel $30 \%$ of the section was then occupied by the reinforcement; the slabs therefore became very inefficient, and stress levels in different layers of reinforcement varied considerably from the mean;

(b) areas of the slab always in compression, that is, both during construction and in service, would finally be excessively overstressed for the design grade of concrete, and a high strength mix for the first lift would be required;

(c) it was suspected that the well known behaviour of the flat slabs could only be assumed provided high loads kept well away from any free edge that occurred during construction. 
190. First lift bays were $10.5 \mathrm{~m}$ long by $24.0 \mathrm{~m}$ wide and extended beyond a station column by quarter span, that is, construction joints caused cantilevers a quarter span long. Second lift bays were the same size, but were arranged midspan to midspan of station columns. In order to maintain the best progress, the Contractor wished to follow with the second lift closely behind the first, approaching the free edge by threequarters of a span. The effect of this loading sequence was checked by finite element analysis and it was demonstrated that when the high load approached the discontinuity by less than $1 \frac{1}{2}$ spans the bending moment distribution in the first lift began to depart from the usual flat slab pattern; when the load approached the middle of the span next adjacent to the free edge, the distribution no longer resembled the usual pattern at all.

191. Of particular interest was the marked tendency of the first lift to span from side to side of the station, that is $24 \mathrm{~m}$ at points near the centre of spans between station columns (Fig. 10). In other words the intrinsic stiffness of longitudinal 'column strips' was insufficient to prevent the development of large mid-span movements in the transverse direction. The distribution of bottom tensile reinforcement, determined by the original design, clearly suited the behaviour of the completed slab and it was intended simply to increase the density of steel in the first lift where necessary, to cope with the temporary conditions, which should not therefore cause any departure from known flat slab behaviour. As has been said earlier, stresses in lower zones of the completed slab due to construction loadings could not readjust to conform with the distribution that would have obtained had the section been completed in a single lift.

192. Finally, it was decided that the measures that would be required to be confident of success using a $600 \mathrm{~mm}$ first lift were beyond reasonable limits and an $800 \mathrm{~mm}$ section was considered; this slab satisfied all the design criteria except that loading near to a free edge had to be restricted to avoid undesirable effects which would still arise. The falsework could just take the load, albeit with considerable strengthening, and since the ticket hall and mezzanine floors could also carry the load with a reasonable quantity of propping, construction proceeded using the $800 \mathrm{~mm}$ first lift.

193. Consideration of thermal and drying shrinkage stresses showed that conditions in the completed slab would not be materially different from those assumed for the main design with one possible exception: it was thought that during hydration of the second lift restraint at the interface of the two parts of the slab might cause some disruption of the core. Such damage had been recorded in similar circumstances elsewhere. It was not possible to follow with the second lift until the first had gained its 28 day strength, and had cooled, and this would possibly aggravate the tendency to crack. There was little that could be done to prevent damage other than by maintaining careful control and curing of concrete operations. Temperature records were made using thermocouples which indeed showed high temperature gradients at the interface. The magnitude of the attendant tensile stresses was such that it was decided to take a number of $100 \mathrm{~mm}$ cores from the completed slab for microscopic analysis but the results of this examination showed no damage.

\section{Professor A. L. L. Baker, Imperial College}

Tunnelling engineers are naturally mainly concerned with successfully and efficiently making a hole. I am naturally concerned with how the load is to be carried. I was recently at a European conference discussing future regulations governing quality control of concrete. These are likely to be imposed by the EEC in about ten years' time. Most of the discussion was by people who I do not think had gone much outside the concrete laboratory. They knew all about standard deviations, statistical probability, the types of distribution, etc. On such a basis their conclusions were good, but what I felt was lacking was knowledge of the difference between the laboratory and the actual site.

195. This is a marvellous opportunity to ask the Consultants and Contractors about this. I imagine they would accept as a design basis the British Standard Code which assumes concrete on the site to have two-thirds of the characteristic strength obtained 


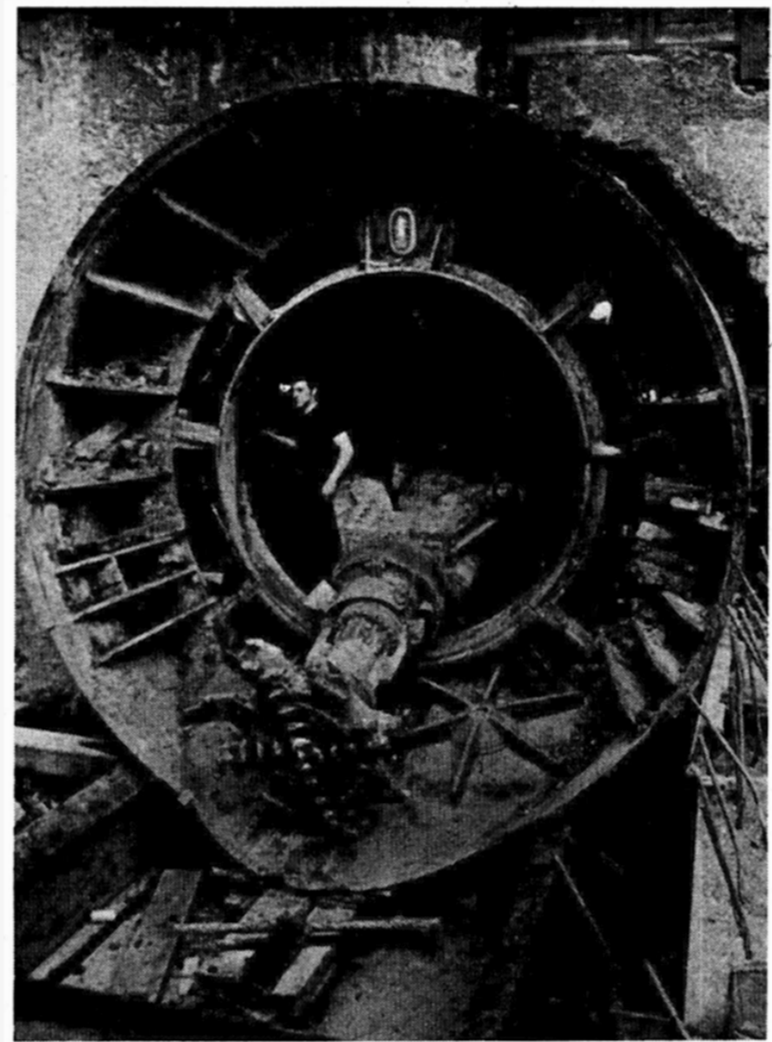

Fig. 15. Anderson Mavor excavator

in the laboratory, and the design load to be 1.4 times the estimated characteristic load. What do they consider was the actual difference between the strength of the concrete in the structure as compared with the laboratory? Would a partial safety factor of 1.4 applied to the load adequately cover the worst stress condition likely to occur?

196. At the conference there also seemed to be a tendency to reduce the sanctions which the resident engineer can normally impose to make sure he gets the quality of concrete he wants. In the past one could say that when concrete was proved to have about $\mathbf{8 0} \%$ characteristic strength one could impose a test load, to be paid for by the contractors if the concrete was too weak and by the client if it was not too weak. If such sanctions are to be cut out of contracts and codes this could be dangerous. So I would very much welcome a few comments on these points either from the Consultants or the Contractors.

Mr C. N. P. MacKenzie, John Mowlem \& Co. Ltd

I was agent for part of the tunnel contract and wish to add a few words about the specialized plant.

198. Problems with the segment press were mentioned. These were mainly associated with producing a dimensionally acceptable product. Of one type, $90000 \mathrm{had}$ to be produced, and there were three moulds to do it with. Since it is a mechanical 


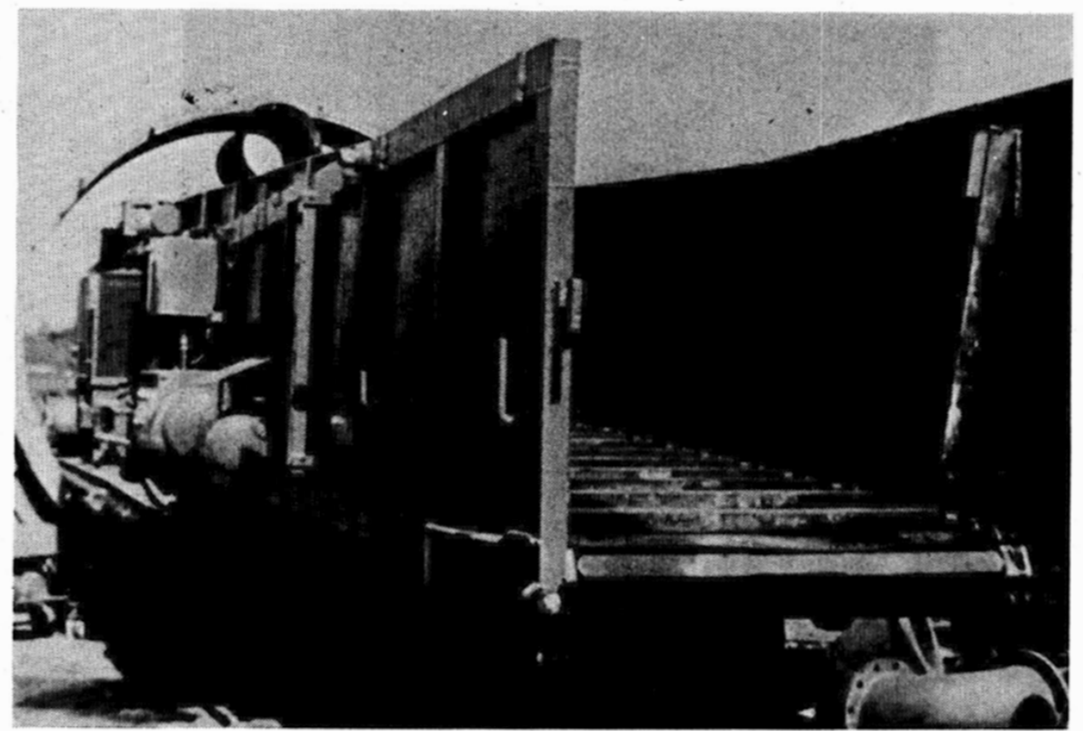

Fig. 16. Shuttle car (showing conveyor floor)

process, wear occurred on the moulds. When the mould wear reached $0.3 \mathrm{~mm}$ the moulds were built up by a welding process and reground to the specified dimension. This was allowed to continue for some time and the segments were then ground to $0.05 \mathrm{~mm}$ tolerance.

199. The two shields were of the standard Greathead type; one was produced by Priestley and one by Lawrence, and each was equipped by those company's erectors. The boom cutter loader is a self-contained electrically powered tunnelling machine which can move backwards and forwards in the tunnel, on a sledge. It has both electrical and hydraulic equipment and can also be used on the surface by hitching it on to a generator. As it cuts the clay $75 \%$ goes on to the boom and the remaining $25 \%$ drops past the boom and is picked up the next time. It is hydraulically driven and quite efficient but stalls on claystones and has low momentum forces. Fig. 15 shows the boom in its lowered position and demonstrates how far it comes forward. The boom is actually telescopic and this machine can pull back into the conveyor and thereby assist the windmills. No loading device can really take the full capacity of this cutting machine. This installation has been repeated at Newcastle.

200. There was no timber of any kind in the face. In this particular Priestley type of erector, erection takes place from the top downwards and each segment is secured on the erector by a locking pin which goes into the signal bracket hole. It looks pretty congested but there is quite a lot of space for men to work.

201. Clearly people would like comparisons between the Anderson Mavor and the Westphalia. In this case I think it is clearly a case of the former being the better for this application. While the Westphalia is a good, well put together machine, the Anderson Mavor is a superb machine and the down time is simply not measurable in normal terms. I think that on the entire project there were $4 \mathrm{~h}$ down time, and this was for modification rather than failure. It has an electric drive through a gear box to a cutting head with substantial force, for chopping up claystones, etc. It was designed for working in sandstone, and therefore has that capability built into it.

202. One other item of plant which has been specially mentioned is the shuttle car 
system for removal of spoil from the tunnel face. Essentially this was of large steel boxes with a very powerful flight bar conveyor along the floor, self-propelled on two bogies (Fig. 16). The cars carry 21 tons of spoil and each when fully loaded weighs $40 \mathrm{t}$. Each has an $80 \mathrm{hp}$ diesel engine which drives the hydraulic pump to both bogies. When a car is under way, all the flow can be diverted to one bogie, thereby doubling the speed. It also has electrical equipment which plugs into the mains at the face so that it does not create fumes at that point. There is a fume diluter under the floor which is used in conjunction with tunnel ventilation to control the build-up of noxious fumes in the tunnel. The diluter is efficient and is an efficient silencer.

203. In the crossover tunnel, as has already been described, a hydraulic excavator was used to excavate the clay. It is an interesting machine inasmuch as it not only has the normal operation of the boom forward and backward, but it can also pivot horizontally so that it can act sideways to excavate to the face. This was used in conjuction with a Mowem designed stage working independently of the face. The erectors could handle $0.5 \mathrm{t}$ segments at a radius of $4.5 \mathrm{~m}$.

\section{Mr R. P. Burgess, Robert L. Priestley Ltd}

Talking of British equipment and also tunnel segments, it may be of interest that my firm has been discussing manufacture of segments by a press with an East European country, and they are very concerned about whether they can manufacture individual segments to $3 \mathrm{~mm}$ tolerance.

205. When considering equipment there are 'horses for courses', and I think Mowlems chose the right horse for their course. Full faced machines are very expensive and not necessarily economic for all jobs. Our own conventional full faced machines have averaged about $7 \%$ down time; this is slightly higher than Mr MacKenzie's figure, but the output is much higher, and for longer tunnels there is little doubt that full faced machines can be the right choice.

206. Erection of segments is of course important, in some cases more important than the equipment with which to dig a tunnel. One example of this was in the Channel Tunnel, where lining erection was a critical factor in the overall construction cycle. For speed of erection when using a wedge type lining, maximum benefit is obtained with the wedge in the crown; when jacking from the knee joints it is probably preferable to use jacks rather than wedges, but this point is no doubt open to debate.

\section{Mr F. C. Rattue, Sir William Halcrow \& Partners}

There are references in the Paper to the problems of working at Heathrow Airport. The difficulties were of two basic kinds arising from restricted headroom and restricted access. At the main site the overall restriction was $3.7 \mathrm{~m}$. Every item of plant over this height to be used on the works had to be notified to the British Airways Authority for approval, and its operation was subject to conditions laid down to ensure the safety of the airport.

208. To enable survey work to be carried out at the airport, one had to go to a survey station outside the site boarding, for which a work permit was required. All personnel engaged on this work were issued with identity documents. The control exercised by the Authority was strict. All plant movements for the site were subject to work permits. Much of the plant was too big to go through the approach tunnel and was taken overground across runways, sometimes at night because the runways were not being used then, and sometimes by day over a runway when an alternative runway was being used. Works movements had to be carried out to a strict time-table, at times specified by the Authority and under their control. Using this system, two running tunnel shields were removed from the central area together with all their subsidiary plant, many minor plant movements took place and the whole of the equipping of the over-run tunnels site was carried out. 
209: The over-run tunnels site was restricted due to the traffic problems that exist there. At one stage the site extended into the carriageway of Cromer Road and was divided by the car park entrance road. As the scope of the work increased, the site layout needed changing and approval was given to rearrange the site and move the car park entrance.

210. I do not want to give the impression that work was made difficult-it is a difficult situation. I should like to end by expressing thanks for the assistance and cooperation received from the liaison staff and the various departments of the British Airports Authority, particularly roads administration, telecommunications and operations. With their help and the good will of the Contractor the works were completed without ever endangering the operation of the airport or the safety of its passengers.

\section{Mr K. W. Torpey, Mott, Hay and Anderson}

Mention is made in the Paper of the extensive service diversions which were necessary for the construction of the cut-and-cover section of the railway. I understand that there were ten statutory authorities involved at one time on the site. Service diversions can be a very difficult and costly problem, particularly when cut-and-cover construction is used in an urban area. For example, the cost of diversions for construction of a subsurface ticket hall under a street in central London can amount to about $20 \%$ of the civil engineering cost. I would like to know what the actual percentage was on this project.

212. As more and more railways are built underground in cities around the world, attempts are sometimes made to provide means of reducing noise and vibration from the operating railway. I appreciate that it is a little early to say how successful this may have been on this project, but $I$ should like to know what the percentage increase in cost was for providing the track trays, including all the necessary ancillary works, over the length in which they were installed.

\section{Mr B. F. Gonsalves, John Mowlem \& Co. Ltd}

In reply to certain criticism of the concept of using an expanded wedge-block lining to cater satisfactorily for most types of clay normally met with in a shield driven tunnel, Mr Lyons inferred that because in the past the Donseg, with slip-on beads, had proved adequate and economical, there was no reason why the present lining should not function as well under similar conditions. There are two points relevant to this inference.

214. First, Donsegs have twelve tapered segments, as against the two wedge segments in the present lining. It is therefore possible to expand the former by up to six times as much as the latter, for the same horizontal movement of the wedge segments, and so give the contractor a far greater tolerance in allowing for coming on of the clay behind the tail when selecting a diameter for the shield carcass. Secondly, with a hand shield drive there is very little disruption caused to the work by having to overcut and fix beads, as the miners are perforce already working in the face.

215. This situation has been radically altered by the introduction of sophisticated machines to carry out the mucking operation, which have allowed the replacement of the miner by a different type of operative. Any interruption to the digging cycle now results in a considerable loss of progress. Further, the types of men now being used in mechanized drives are no longer adept at working in the face with clay spades, resulting in considerably more expense and loss of time in fixing slip-on beads than hitherto.

216. Basically, the segments as used on Contract 540, and elsewhere since, would appear to strike a reasonable mean between size, weight, ease of handling and the number of segments to be handled. The problem appears to lie in the small margin of tolerance this lining allows to the contractor in making his initial 'guesstimate' of the probable behaviour and variation of the clay which he is going to meet along the length of the 
drive. This problem is overcome quite simply by expanding the segments by primary movement in line with, rather than at right angles to, their circumference.

Mr R. Watts, Balfour Beatty Construction Ltd, formerly John Mowlem \& Co. Ltd I first appreciated the problem of making tunnel segments in 1960 while working for Edmund Nuttall on the MWB 100 in. water tunnel at Staines, where standard concrete moulds were bred off one cast iron master. I realized that the methods used at that time and since were not compatible with the needs of mechanical digger shields. I spent many years looking for and eventually found what I thought was the answer in the hydraulic press developed by Fielding and Platt for the production of kerbs and paving slabs. I argued that a tunnel segment need not be any bigger than a paving slab, nor any thicker than a kerb, so all that was necessary was to combine the two in the same product. The concrete produced must, I felt, be of a very good quality as all slabs and kerbs are left out in the weather and stand up remarkably well compared with ordinary vibrated concrete products in similar circumstances.

218. I was able to take the matter further in $\mathbf{1 9 7 0}$ when I was involved in tendering for a $100 \mathrm{in}$. water tunnel for which the system seemed ideal. However the tender was not successful and it was suggested that the idea might be used for the design of segment required for the Piccadilly Line. Upon investigation it became apparent that this method of manufacture might be the only way of obtaining the tight tolerance required by Sir William Halcrow and Partner's design.

219. Although the machine chosen was capable of keeping pace with one 100 in. water tunnel, it proved a bit over-stretched trying to keep pace with two $12 \mathrm{ft}$ running tunnels, both of which were semi-mechanized. Would it have been possible to consider carrying out the drives one after the other, rather than both at the same time, as was required to meet the tight programme laid down?

220. The precasting plant worked well in the circumstances-the peculiarity of the mix needed, the tight dimensional tolerance required and the short one-off nature of the contract. If the Authors proceeded with the same design again, would they be able to give any latitude in the requirements?

221. In $\S 31$ the use of cut-and-cover techniques is justified by the tender prices. Was this justification born out in the final analysis?

222. Was the problem of noise considered? The working site at Hatton Cross was so close to the end of the runway that for the greater part of the summer days $10 \mathrm{~s}$ in every 55 were lost for any meaningful conversation. This put a very severe strain on the staff and operatives. Could this have been avoided by keeping the open cut work and site further away from the end of the runway?

\section{Mr D. B. Carter, Mott, Hay \& Anderson}

A casting tolerance of $0.05 \mathrm{~mm}$ for the concrete tunnel lining segments has been mentioned in the discussion. This figure is much smaller than is generally adopted, even for curved radial joint surfaces. Would the Authors please state to which dimensions this tolerance applied and why such accuracy was considered necessary; could they explain how compliance was measured.

224. Referring to the concrete tunnel linings of the wedge type, how much variation in lining perimeter was allowed by the taper on the wedges and the range of positions to which they can be driven? Was it found in practice that this was sufficient to offset variations in the size of the excavation, or was it necessary to provide more than one size of wedge? Was it found that the variations in the size of the excavation occurred gradually over a number of rings, or were the main variations caused by local changes in ground quality or by the shield having remained stationary for a period?

225. In $\$ 65$ it is stated that expanded concrete rings give smaller surface settlements than bolted grouted lining. Would the Authors please give details of the measurements which give rise to this conclusion. 
Dr T. K. Chaplin, Dept of Civil Engineering. University of Birmingham

$I$ would be glad for information on the following points:

(a) tolerance for wander of secant piles and values actually found during excavation;

(b) design assumptions for horizontal earth pressure, its total and distribution on the secant piles and diaphragm wall, from the natural soils and with the added effect of loads from aircraft;

(c) the design considerations for the diameter and thickness of the piles and diaphragm wall, and how far these were based on the assumed earth pressures and on the practical considerations of easy construction through difficult ground.

227. In the tunnel design, what assumptions were made about the shear forces between segments and ground and what was the tolerance assumed for cutting by shield and/or overbreak during manual excavation?

228. If there were any slight observations of earth pressure and thrust in the lining I would be glad to have some details. In the years 1952-1955 I was concerned with a great deal of earth pressure measurement on tunnel linings at the Building Research Station and there is a considerable amount of information there which has not so far seen the light of day.

229. Regarding $\$ 36$, I would have expected trouble of this sort to be produced by an old course of the River Crane in its recent geological past. I am sure that deeper boreholes must be supplemented with probe tests, where these are feasible, additional shallow boreholes to clay, or even geophysical investigation, so as to avoid trouble.

\section{Messrs Jobling and Lyons}

Mr Clark refers to the disturbance of the groundwater condition by the construction of the cut and cover tunnel acting as an underground dam. Before the work started efforts were made to determine the pattern of groundwater flow. A number of trial holes were dug and colour was used to try and identify a general flow, but the results were inconclusive. It was therefore decided to construct a number of siphons under the tunnel as a precaution. Inspection of these since the tunnel has been completed have not established a flow pattern but there is no evidence of a build-up of groundwater level on the north side. These negative observations may, however, be due to the very dry weather and the consequent drop in the water-table level. Regarding Mr Clark's remarks concerning road diversions, experience on this job has left little doubt that paying for these on a cost plus basis is the best method of dealing with this type of work. It gave great flexibility in meeting the local authorities' requirements.

231. Mr Stone refers to the reduction of the pile centres. The soil strata was very similar to that shown by the borehole logs except that the rate of ingress of water through the gravels was much greater than predicted from the boreholes. It was the presence of this water that led to the decision to reduce the pile centres by a small amount. Obviously this led to an increased cost because more piles were used to a given length of wall and the extra cut into completed piles gave a slower rate of boring on the male piles. The additional cost, however, was offset to some extent by using a weaker mix concrete in the unreinforced female piles.

232. Mr King states that, to his mind, the tolerances for the curved cross joints of the tunnel segments are far too tight. They are tighter than we would like them to be, but they cannot be reduced if unreinforced concrete is to be used for the segments.

233. The design of the concrete segments for Contract 508 was an extension of the method used for the design of the Victoria Line segments. On the Victoria Line, the segment cross joints were curved only in a plane normal to the axis of the tunnel lining causing a cylindrical contact surface. However, for the design of the Contract 508 segments, a second curve in the plane parallel to the axis of the tunnel was introduced, giving a domed contact surface. These contact surfaces produce, under load, an 
elliptical contact zone whose area governs the magnitude of both the compressive contact stresses and their associated bursting stresses behind the joint. These stresses, therefore, govern the load carrying capacity of the joint. Theoretical and experimental work carried out for both the Victoria Line and Contract 508 indicated that the strength of the joint increased along with the radius of the segment contact surfaces, but that the flatter the contact surface the more sensitive it became to shifts in the point of contact caused by localized variation in profile. In order, therefore, to ensure that the point of contact always lay within the middle third of the segment after the radial displacement tolerance had been applied, it was found necessary to state a tolerance on the radius in the plane normal to the axis of the tunnel of $\pm 0.05 \mathrm{~mm}$. This tolerance was the same as that specified and maintained for the Victoria Line segments.

234. Mr King is incorrect in his statement that the $80 \mathrm{~mm}$ horizontal travel of the wedge block gives only $5 \mathrm{~mm}$ circumferential movement for expanding the ring. Ignoring the fact that the wedge can be over-shoved, thus creating more movement, the available circumferential movement for two wedge blocks is $(2 \times 80 \times 120) / 600 \mathrm{~mm}$, i.e. $32 \mathrm{~mm}, 2 \mathrm{~mm}$ more than he states he requires. The amount of movement of the clay in any particular area tends to remain fairly constant provided that the shield makes steady progress. Once the drive has settled down to a steady rate it is less trouble to adjust the bead on the cutting edge at a weekend to obtain the optimum circumference than to make moulds for various sizes of wedge blocks. When this is done, there are always wedge segments left unused at the end of the drive which have little residual value.

235. Mr Gonsalves appears to have missed the point completely. The Donseg ring with all the segments the same size expands to a fixed diameter and no allowance can be made for the coming on of the clay; hence the need for a slip-on bead. The bead does not need to be changed very often and in 1958, constructing the Metropolitan Water Board's raw water main in Donsegs behind a K.M. drum digger from a site at Bank Lane, Roehampton, Messrs Kinnear Moodie built 206 rings (about $126 \mathrm{~m}$ ) of tunnel in 1 week. This record stood for many years and is a better rate of progress than was achieved on Contract 508. The current record for one week's driving of $43.5 \mathrm{~m}$ is held by Messrs Nuttall using a BSP Nuttall machine and building wedgeblock rings. On Contract 508, progress with the wedge segment lining (Halcrow) was $20 \%$ faster than progress with the jacked lining (Mott Hay) on the same drive using the same equipment. The problem is not overcome simply by changing to a jacked lining, unless the contractor is being paid on a time basis.

236. Mr Watts asks if the running tunnels could have been driven consecutively instead of concurrently. They could have been, but this would have lengthened the programme and probably increased overheads. In any case, the pressing machine did produce all the rings required in time and neither drive was ever held up for lack of rings.

237. Mr Watts mentions the possibility of relaxing the tolerances for the segments. If the tolerances for the cross joint are increased, it would be necessary to increase the radius of the $3000 \mathrm{~mm}$ curve which would increase the bursting stresses. The concrete used had a strength of $45 \mathrm{~N} / \mathrm{mm}^{2}$ concrete and it would not be desirable to go higher, but in any case it is debatable if doing so would greatly increase the tensile strength.

238. The alternatives are to use reinforcement, which greatly increases the cost per ring, or the use of resin concrete which would also increase the cost. The problem is to keep the line of bearing within the middle third and, to guarantee doing so, that tolerance must be kept at two points on the curve. In practice, the tolerance can be relaxed to some extent when the profile of the curve is known, provided that the surface is within tolerance at the vital points and the line of bearing is in the right place when two surfaces are brought together. The details of the tolerances are given in an Appendix. The accurate gauges for checking of domed joints were made by Salt Engineering Co. (Coventry) Ltd.

239 The variation in lining perimeter obtained within the normal travel of the two wedges combined was $32 \mathrm{~mm}$ and this could be increased to $64 \mathrm{~mm}$ by overdriving the 
wedges The size of cut could have been adjusted by varying the cutting edge bead and adding a tail bead or tail planer. The variation in the ground occurred gradually and was the same for long lengths of drive. The first shift on Monday mornings always required special care, as has always been the case with expanded linings in London Clay. Expedients vary from trimming the clay surface with a shovel or hoe shaped instrument to breaking off the end of a wedge that cannot be driven in. As the gaps between the wedges are filled with dry-pack concrete, the latter expedient is not so drastic as it seems at first sight.

240. Measurements of ground movements were taken on the Victoria Line which indicated that they were smaller, and surface settlements were less, for expanded concrete rings than for bolted grouted linings, but as the circumstances were different there was always room for argument for those not wishing to be convinced. However, on the Fleet Line stage I, measurements of grotund and surface movements were taken by the University of Durham and the Transport and Road Research Laboratory in conjunction with Messrs Mott Hay and Anderson and Sir William Halcrow and Partners under almost identical conditions over and around running tunnels being driven in bolted grouted cast iron rings under Green Park and expanded concrete linings under Regents Park, ${ }^{1}$ and the average movements were clearly less in the latter case. The reasons probably are that the ground is supported as soon as the ring is expanded in one case, whereas the ground is not supported until the grout has set in the case of a grouted lining: in the case of an expanded ring the lining can be stressed to what is thought to be its final load on erection: an expanded lining can be erected more quickly and the tunnel driven faster, giving the ground less time to move.

241. Mr Stone and Mr Sims both refer to the comparative cost of similar sections built with secant piles and with a reinforced concrete box built in a sheet piled excavation. In one of the deeper sections the two types of construction were adjacent, the reinforced concrete box construction being chosen where there were no nearby properties. Assuming that the sheet piles could have been withdrawn, the reinforced concrete box construction should have been rather cheaper than secant pile construction, probably by $10-15 \%$. In fact, however, because of the severe twisting of the sheet piles, consequent water problems, and the necessity of leaving the piles in the ground, the actual cost of construction was considerably above the secant pile part. Another consideration in this case was the presence of some large services very close to the secant pile wall. The statutory authority advised that while the services could remain in position for secant piling, they would have insisted on a diversion (at a cost of about $£ 100000$ ) had sheet piling been used. This was not taken into account in the cost figures above.

242. Professor Baker refers to the ratio between laboratory mixed and tested concrete compared to the on site strength. Assuming the cube strengths to be representative of the placed concrete strength, then in the cut-and-cover part of the works, rather more than two-thirds of the laboratory strengths was achieved on average. Regarding the sanctions which the resident engineer can impose, it seems essential for these to be retained. It should be noted, however, that if a cube fails, the concrete from that batch has been in place for some time before the cube is tested and may well, by then, be in the middle of a structure. The decision to cut out a marginally bad batch of concrete is then very difficult. It is liable to disrupt the programme, will be very costly and the remedial concrete may be very difficult to place. The resident engineer's real safeguard is to ensure that good concrete of consistent quality is being used on the works. In the cutand-cover contract a batching plant was used on the site and the control was very good. There were very few instances of test cubes not attaining their specified strength.

243. In reply to Mr Torpey the service diversions were extensive over about half the length of cut-and-cover works, particularly the GPO services. The cost of service diversion was about $£ 1$ million on a contract of about $£ 6$ million for the civil engineering work. Probably a better comparison is about $£ 900000$ for service diversion on about $£ 4$ million for civil engineering works for those parts of the tunnel built under urban streets. 
244. Regarding the noise and vibrations, tests have shown that the antivibration bearings have eliminated about $90 \%$ of the train-induced vibrations which enter the ground in those parts of the cut-and-cover railway with traditional ballasted track. Measurements of ground borne vibrations in insulated areas have, however, been made very difficult because these are masked by the vibrations caused by road traffic. The inclusion of the antivibration track trays proved very expensive and increased the cost of this section of work by about $25 \%$, i.e. by about $£ 500 / \mathrm{m}$ of completed twin track tunnel.

245. In reply to Dr Chaplin, the specified tolerance for wander of the secant piles was $\pm 25 \mathrm{~mm}$ for the location of the pile centre at ground level with a maximum deviation from the vertical of $40 \mathrm{~mm}$ in $5 \mathrm{~m}$. Lateral deviations were measured over certain lengths where it was thought there might be some fouling of the concrete lining. The measurements were taken at track level, $6 \mathrm{~m}$ below ground level, where the specification would have permitted a tolerance of $\pm 75 \mathrm{~mm}$. The results for 100 consecutive piles were that one had a deviation of more than $75 \mathrm{~mm}, 16$ deviated between 75 and $50 \mathrm{~mm}$, 30 deviated between 50 and $25 \mathrm{~mm}$ and 53 had deviations of less than $25 \mathrm{~mm}$. Longitudinal deviations were not measured, but only the female piles would be free to deviate in such a way, the male piles being constrained by the former. Thus a $100 \%$ improvement in accuracy would be expected. Certainly loss of pile interlock occurred very rarely, and when it did this was generally in the clay strata, where there was no problem with ingress of water.

246. Figure 17 gives general information on design criteria for a typical secant piled wall. These were used only outside the airport so aircraft loadings were not considered.

247. As stated in $\$ 10$ the original design was for $800 \mathrm{~mm}$ thick diaphragm walls, the thickness being arrived at by standard design methods. The diameter of the secant piles ( $880 \mathrm{~mm}$, not $890 \mathrm{~mm}$ as stated in the Paper) was proposed by Waddingtons as the nearest to $800 \mathrm{~mm}$ from their limited range of available tube diameters. Naturally construction aspects were considered, and the relative costs of different pile diameters, but basically the diameter arose from design considerations.

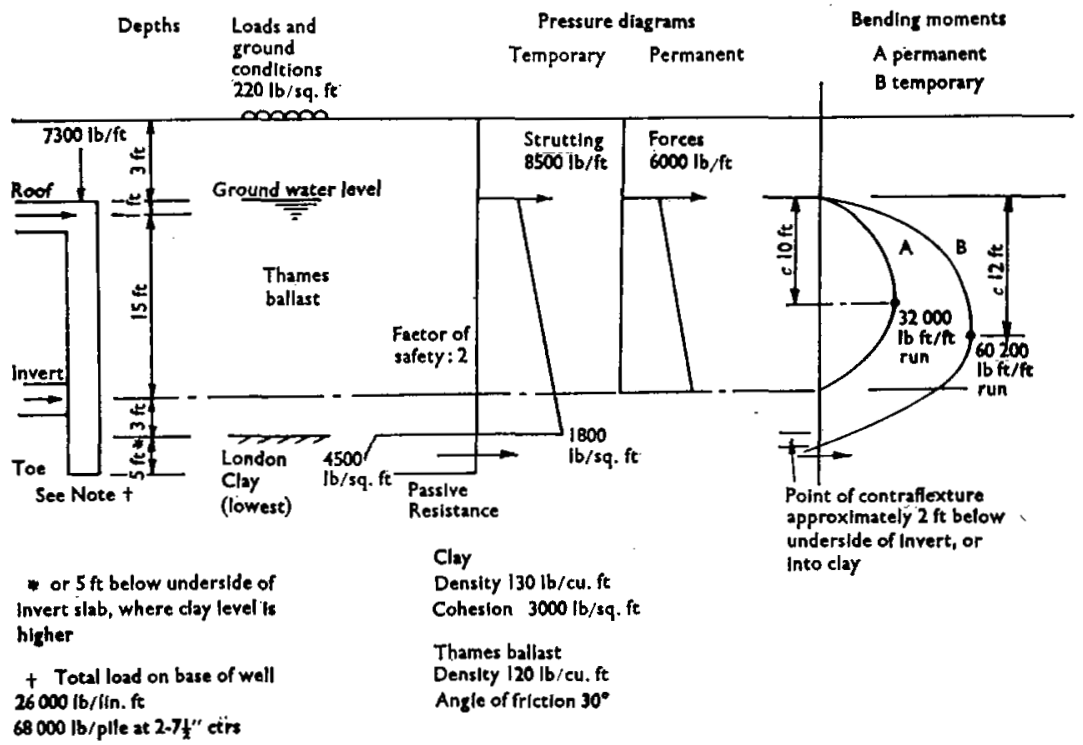

Fig. 17 


\section{DISCUSSION}

248. For the design of the concrete linings no allowance was made in the calculations for the shear forces between the ground and the lining. This leads to conservative results. There was no manual excavation for the concrete linings and the shield trimmed the excavation to the outside diameter of the lining, and hence no tolerance was allowed for in the design. However, a $12 \mathrm{~mm}$ bead was fixed to one shield to assist guidance and this required a small degree of extra jacking to lock up the lining.

249. No earth pressure measurements or thrust readings were taken, because sufficient data had been collected from Victoria Line experiments. However, ground movements on a similar contract have been monitored, as indicated in $\S 240$.

\section{Reference}

1. BARRATT D. A. and TYLER R. G. Measurements of ground movements and lining behaviour on the London Underground at Regents Park. Transport and Road Research Laboratory, Report 684, TTRL, Crowthorne.

\section{Appendix}

\section{Specified tolerances for concrete linings}

Base surface: theoretical extrados of lining.

Extrados and intrados: each $\pm 1.0 \mathrm{~mm}$.

Thickness: not stated (interpreted from above as $\pm 2.0 \mathrm{~mm}$ ).

Length of segment: angle subtended at centre \pm 2.0 minutes of arc.

Longitudinal joints: (domed).

On $3000 \mathrm{~mm}$ radius curve: a surface tolerance of $\pm 0.05 \mathrm{~mm}$.

On 11250 radius curve: no surface tolerance stated.

On 11250 radius itself: $\pm 3.0 \mathrm{~mm}$.

Centres of above: within $5.0 \mathrm{~mm}$ of theoretical position.

Circle joints: $\pm 1.0 \mathrm{~mm}$.

Helical (wedging) joints: not mentioned.

\section{Interpretation of specified tolerances}

Base surface: method of pressing fixes domed cross joints relative to intrados, not extrados.

Thickness: interpreted as $\pm 2.0 \mathrm{~mm}$, i.e. $\pm 1.0 \mathrm{~mm}$ on each of extrados and intrados. However, since the centre of the domed joints was fixed relative to the intrados, this constituted a relaxation of the extrados tolerance.

Length of segment: interpreted as a tolerance on outside circumference of a ring set up (horizontally) with keys central and all domed joints touching. $0^{\circ} 02^{\prime}$ for 22 segments at $4115 \mathrm{~mm}$ dia. gives $26 \mathrm{~mm}$ on circumference.

Domed joints: allowed surface tolerance from theoretical dome in each direction $\pm 0.05 \mathrm{~mm}$. Tolerance on 11250 radius ignored. Positions of centre of radii: contact point between segments set up in ring to be within $5 \mathrm{~mm}$ of centre of joint.

Helical joints: surface tolerance $\pm 0.05 \mathrm{~mm}$ from theoretical.

Circle joints: tolerance on width of segment $\pm 2.0 \mathrm{~mm}$.

\section{Method of measuring}

Thickness: measured with sliding vernier calipers. Some variation over segments ignored.

Length of segment: tape around complete ring set up horizontally.

Width of segment: tape on mould.

Domed joints: templates to $3000 \mathrm{~mm}$ and $11250 \mathrm{~mm}$ were made, to a tolerance 10 times better than required on segment (i.e. $\pm 0.005 \mathrm{~mm}$ ). Departures from templates measured with feeler gauges. Readings taken on standard grid. 
Helical joints: straight edge and feeler gauges. Standard grid for measurement.

Contact point of domed joints and angle of helical joints: full ring set up horizontally, and checked for shape by taking radii measurements with steel tape. Contact between segments investigated with feeler gauges.

\section{Frequency of measuring}

Thickness: every segment checked.

Length (i.e. circumference of ring): a few rings were set up at the start of the job, then no more. The specified frequency of one testing per 100 cast was related to a normal yard, with dozens of moulds. Only three moulds per segment type were used in this process, and repeatability of dimensions with coarse tolerances and formed by the moulds was good.

Width of segment: moulds measured at start of job.

Domed or helical joints: measured on a grid and recorded; three segments per shift (one from each die). In addition, a large number of random unrecorded checks were done, particularly as remedial grinding was done.

\section{Achieved tolerances}

Thickness: the tolerance was relaxed at the Contractor's request from $\pm 2 \mathrm{~mm}$ to -2 to $+4 \mathrm{~mm}$. There did appear to be an improvement in the reject rate following this (it was about $2 \%$ lower). However, the number of segments between +2 and $+4 \mathrm{~mm}$ rose to $20-30 \%$ after this initial improvement and the overall reject rate also rose. It seems likely that the relaxed tolerance made the work easier without affecting the number passed.

Length of segment: circumference of rings carefully set up horizontally varied from $1 \mathrm{~mm}$ to $14 \mathrm{~mm}$ over the maximum limit, i.e. was $27 \mathrm{~mm}$ to $40 \mathrm{~mm}$ longer than nominal.

Width of segment: well within tolerance.

Domed and helical joints: a feeler gauge of 7 thou $(0.18 \mathrm{~mm})$ was used as a 'go-no go' gauge with the templates or straight edges. In general, if the 7 thou feeler gauge could be inserted, some remedial work was done on the segment, and this tolerance was finally achieved. When the moulds were in good condition, this tolerance was usually achieved fairly easily, readings of $4-6$ thou from the template being typical. However, on worn moulds, readings were sometimes 15 or even 20 thou. 